\title{
Telepsychiatry: effectiveness and feasibility
}

\author{
This article was published in the following Dove Press journal: \\ Smart Homecare Technology and TeleHealth \\ I April 2015 \\ Number of times this article has been viewed
}

\author{
Amy Gajaria' \\ David K Conn ${ }^{1,2}$ \\ Robert Madan ${ }^{1,2}$ \\ 'Department of Psychiatry, University \\ of Toronto, Toronto, ON, Canada; \\ ${ }^{2}$ Department of Psychiatry, Baycrest \\ Health Sciences, Toronto, ON, Canada
}

\begin{abstract}
Providing psychiatric services by real-time videoconferencing has been increasingly adopted as a method of reaching hard-to-serve populations since the early 1990s. As the field has expanded, a growing body of research has developed investigating both how telepsychiatry compares to in-person psychiatric care and how effectively telepsychiatry can be implemented in routine clinical care. A narrative review was performed to consider the evidence that telepsychiatry is feasible and effective across a variety of patient populations and clinical settings. There is a growing body of evidence investigating the efficacy of telepsychiatry when used for psychiatric assessment and treatment in the adult, child, and geriatric populations. Though studies vary in quality, they generally demonstrate that telepsychiatry is effective across multiple age groups and clinical settings. Telepsychiatry is generally well accepted by patients and clinicians and is feasible to implement, with the suggestion that some patients may actually prefer telepsychiatry to in-person treatment. Issues to consider in the implementation of telepsychiatry services include funding and reimbursement, medico-legal issues when provision crosses legislative boundaries, incorporation into existing health systems, and crosscultural considerations. Future directions for research and practice include a need for higher-quality efficacy studies, consideration of data security, increased attention to low- and middle-income countries, and the introduction of novel technological approaches.
\end{abstract}

Keywords: efficacy, service delivery, telemental health, videoconferencing

\section{Introduction}

Telepsychiatry can be defined as the delivery of health care and the exchange of health care information for purposes of providing psychiatric services across distances. ${ }^{1}$ The term is most frequently applied to the use of real-time videoconferencing. The term "e-mental health" refers to mental health services provided through any electronic medium including the Internet, telephone, or facsimile transmission. ${ }^{1}$ Telemental health is an intentionally broad term referring to the provision of mental health care from a distance. ${ }^{2}$ It includes mental health assessment, treatment, education, monitoring, and collaboration. ${ }^{2}$

The first published accounts of telepsychiatry date back to the late 1950s when a two-way closed-circuit television system in Nebraska was used for medical and educational purposes with a focus on psychiatry. ${ }^{3}$ The term "telepsychiatry" was first used in a report from Massachusetts General Hospital in Boston, MA, USA in 1973.4 The field grew slowly until the 1990s when improved technology paved the way for further growth and development. The primary impetus has been the capacity to provide services to rural and underserved communities with further expansion to other underserved populations. 
A recent report focused on telemedicine around the globe, based on survey responses from 114 World Health Organization member states, found that only $13 \%$ of responding countries had established telepsychiatry programs and only $24 \%$ reported having any telepsychiatry services. ${ }^{5}$ American and Southeast Asian regions had the highest number of services with African, Eastern Mediterranean, and Western Pacific regions reporting the lowest availability of services. Telemedicine is a significant and rapidly growing component of health care in the United States. There are currently about 200 telemedicine networks, with 3,500 service sites in the US. ${ }^{6}$ The Veterans Health Administration delivered over 300,000 remote consultations in 2011 using telemedicine and over half of all US hospitals now use some form of telemedicine. ${ }^{6}$

It is difficult to obtain data on actual numbers of telepsychiatry services provided in different countries. A Canadian study reported on 14 telepsychiatry programs that provided an average of 238 consultations per year, which was calculated to represent 107 per million people served by the health sector per year. ${ }^{7}$ A report from South Australia described 48 mental health centers which delivered an average of 100 clinical sessions per month. ${ }^{8}$ The Ontario Telemedicine Network reports significant growth in recent years with more than 300,000 people served annually and $71 \%$ of all services provided being in the field of mental health. ${ }^{9}$ However, the evidence would suggest that in spite of the potential benefits of telepsychiatry, the field is still in its infancy in most countries around the world.

Recent technological developments allow for easier access to secure videoconferencing utilizing personal computers or tablets as opposed to the previous requirement to use studios, which are most often located in hospitals. Other recent innovations include trials of asynchronous store-andforward approaches, which allow clinicians to efficiently review patient information without direct interaction, and telehomecare, which allows monitoring of patients in their own homes. ${ }^{10}$ In order for efficacious interventions to translate to clinical practice, clinicians and patients must be willing to consider the intervention and be satisfied with it. The intervention should also be acceptable to administrators and policy makers based on evidence of cost-effectiveness and feasibility. ${ }^{11,12}$

In light of the ongoing expansion of the field with new developments and opportunities, this paper will provide an updated narrative review of the telepsychiatry literature as of November 2014 with a focus on feasibility and effectiveness. The major focus of this review is on the use of videoconfer- encing for service delivery but other emerging modalities are also considered. Selected articles were initially identified by a search of PubMed using keywords: "telepsychiatry", "telemental and health", "effectiveness", "efficacy", and "feasibility." Article titles and abstracts were reviewed by the authors to see if they were applicable to the themes of effectiveness and feasibility. Selected articles were obtained and their references were reviewed to identify additional articles that may have been missed by the keyword search. We also did some additional focused searches for specific topics within telepsychiatry.

\section{Guidelines and frameworks}

Useful guidelines have been published by international and national associations. Yellowlees et al, on behalf of the American Telemedicine Association, have published practice guidelines for videoconferencing-based telemental health. ${ }^{13}$ Policies and guidelines for the practice of telepsychiatry have also been published in Australia, ${ }^{14}$ South Africa, ${ }^{15}$ and Canada. ${ }^{16}$ Practice parameters (best practices) for the development of telepsychiatry services have also been published. Fourteen principles provided by the American Academy of Child and Adolescent Psychiatry are summarized in Table $1 .{ }^{17}$ The European Momentum Project has also provided a list of eighteen critical success factors for the deployment of telemedicine into daily practice. These include a number of

Table I Principles for establishing a telepsychiatry service

I. The need for services and whether telepsychiatry is an option should be determined.

2. The sustainability of the service should be determined.

3. The patient population, model of health service delivery, and services to be offered should be determined.

4. The required infrastructure should be determined.

5. Legal and regulatory issues should be reviewed.

6. Management strategies for the service should be established.

7. Appropriate equipment and technological specifications should be determined.

8. Quality and clinical outcome indicators should be developed.

9. Rapport, confidence, and collaboration with staff at the patient site should be fostered.

10. Informed consent and assent procedures should be established.

II. The physical setting should be arranged and the virtual relationship should be established to produce an optimal clinical encounter.

12. Method of conducting the assessment should be determined including who, if anyone, should be present with the patient.

13. Procedures for prescribing medications should be established.

14. Patients and families should be informed about procedures for care between telepsychiatry sessions, including procedures for emergency or urgent care.

Note: Data from: Myers K, Cain S. ${ }^{17}$ 
additional factors such as the need to prepare and implement a business plan and a change-management plan, ensuring that the technology has the potential for scale-up and identifying leadership through a champion. ${ }^{18}$ Other related guidelines include international guidelines on online mental health services ${ }^{19}$ and guidelines for psychological services on the Internet and Internet online counseling. ${ }^{20,21}$

\section{Assessment of psychiatric illness}

Psychiatric assessment by videoconferencing has been demonstrated to be comparable to face-to-face assessments using a variety of assessment tools in a small number of randomized controlled trials. A randomized trial of American Indians assessed the reliability of the Structured Clinical Interview for diagnostic and statistical manual Disorders (SCID) by comparing face-to-face assessments and videoconferenced assessments. $^{22}$ Each subject had a SCID assessment in both formats, with randomization of the order of assessments. It was found that there were no statistical differences between formats, with the exception of past-year substance dependence and abuse. A meta-analysis of 14 studies found telepsychiatry to be similar to in-person care based on objective assessment instruments or satisfaction scales with no difference in accuracy or satisfaction between the two modalities. ${ }^{23}$

In addition to studies demonstrating comparable diagnostic assessments, videoconferencing has also been shown to be comparable to face-to-face assessment when administering standardized questionnaires or assessment tools. For example in a study involving 50 subjects previously exposed to antipsychotics, four independent raters used the Abnormal Involuntary Movement Scale to assess for neuroleptic-induced involuntary movements. ${ }^{24}$ Two of the raters assessed the patient face-to-face and two different raters used videoconferencing technology to perform the assessment. No significant differences were found between the findings of the raters. Similarly, a study involving 71 subjects found no difference in reliability in the administration of the mini mental state examination (MMSE) when performed by teleconference compared to in-person assessment. ${ }^{25}$ A study investigating the use of telemedicine for neuropsychological evaluation revealed that patients were satisfied with the process of the evaluation in this format. The authors concluded that the process was feasible and appeared to be comparable to in-person evaluation. ${ }^{26}$

\section{Treatment using telepsychiatry}

A recent comprehensive review by Hilty et al included a summary of 39 telepsychiatry outcome studies, concluding that the results are encouraging, with evidence that videoconferencing appears to be as effective as in-person care for most parameters including feasibility, satisfaction, and clinical outcomes. ${ }^{27}$ The largest study, a randomized controlled equivalence trial involving 495 subjects, utilizing a variety of clinical outcome measures, revealed that psychiatric consultation and follow-up delivered by telepsychiatry were equivalent to face-to-face care, ${ }^{28}$ a similar finding to a comparator trial of the treatment of depressed veterans. ${ }^{29}$ A randomized trial involving 140 outpatients compared eight half-hour sessions of medication management and cognitivebehavioral therapy (CBT) over 24 weeks using either face-toface visits or telepsychiatry sessions. ${ }^{30}$ Patients were assessed for response using the Symptom Checklist-90 Revised global distress indexes and Clinical Global Improvement. Participants receiving face-to-face care and those receiving care by telepsychiatry showed improvement with no significant differences between the two groups.

A subanalysis of psychiatric services in a meta-analysis of home-based telehealth revealed a positive relationship between the use of telehealth and outcomes such as medication adherence, self-reported mental health status, readmissions, and emergency visits with an effect size of $1.42 .{ }^{31}$ In a review of the effectiveness of telepsychiatry services for a wide variety of mental health disorders, it was found that the intervention was successful in $55 \%$ of the studies. ${ }^{32}$ The majority of the studies were judged to be of fair to high quality. Areas of study included child psychiatry, depression, dementia, schizophrenia, suicide prevention, posttraumatic stress disorder (PTSD), panic disorder, smoking, eating disorders, and substance abuse.

\section{Providing psychotherapy by videoconference}

Telepsychiatry provides a format that can be used to deliver psychotherapy to areas where there are barriers to accessing mental health services, either because of geographic challenges or limited service providers. A systematic review of psychotherapy via videoconferencing investigated the use of this format to provide psychotherapeutic interventions in general. ${ }^{33}$ The authors discovered that the majority of published studies were based on individual psychotherapy (71\%), with group and family therapy being less commonly studied (17\% and $10 \%$, respectively). The most commonly studied type of videoconferenced psychotherapy was CBT (45\%). Studies had been performed to evaluate the provision of videoconferenced psychotherapy for mood, anxiety, and eating disorders with more limited attention to gambling and 
addiction disorders. A review ${ }^{33}$ found the therapeutic alliance to be positive overall, with a caveat that some individuals may be distracted by the technology. Patient satisfaction was found to be high, except in circumstances where there were technological challenges.

In a study of veterans with PTSD comparing in-person to videoconferenced CBT, it was found that both groups improved and were satisfied. ${ }^{34}$ However, those in the faceto-face group were found to be more comfortable talking in sessions and had better treatment adherence as compared to the telehealth group. This finding shows that there may still be some advantages to in-person psychotherapy when it is available. Patients receiving videoconferenced psychotherapy achieve comparable clinical outcomes as compared to those receiving face-to-face therapy, but some evidence suggests that satisfaction and treatment adherence may be higher in face-to-face treatment provision. Telepsychiatry offers a useful alternative to psychotherapy provision when in-person therapy is not accessible. Outcome data was lacking for many studies reported in the systematic review; ${ }^{33}$ therefore, research using more rigorous methodology would be useful to better understand the effectiveness of telepsychotherapy.

\section{Using telepsychiatry for acute care and emergency consultations}

Yellowlees et al have summarized the application of telepsychiatry in emergencies, noting that it has the potential to reduce emergency department overcrowding, provide much needed care in rural areas, and improve access to care during natural or manmade disasters. ${ }^{35}$ There is evidence that emergency psychiatry consultations can be provided in a safe and reliable manner. ${ }^{36,37}$ Shore et al provide useful guidelines for telepsychiatry emergency management which cover administrative, legal, and ethical issues. ${ }^{38}$ They also describe some key clinical issues such as the reaction and response to intense affect and the need for emergency policies and procedures to be in place. Rural perspectives are also considered including the greater likelihood for individuals to possess firearms. The need for collaboration with local law enforcement officials is highlighted. Disaster planning includes consideration of short-term mental health needs of both victims and first responders. ${ }^{35}$ Recent disasters such as the aftermath of Hurricane Katrina demonstrate the challenge of caring for people with chronic psychiatric illness, many of whom went without care. Telepsychiatry can play a role in such situations, although optimal response would require teams who have been trained ahead of time in disaster management.
McLaren et al studied the use of low-cost videoconferencing within an acute care psychiatric service in the United Kingdom. ${ }^{39}$ They reported on 105 clinical interactions, noting clinical reliability and compatibility with a wide range of clinical tasks. They provided a framework for the classification of user responses including preexisting attitudes and the mental state of the users, as well as technological limitations of the system. Grady and Singleton described the use of videoconferencing to provide coverage to a rural general hospital psychiatric unit, concluding that short-term coverage for purposes of vacation, training, and illness is feasible. ${ }^{40}$

\section{Feasibility, barriers and cost-effectiveness}

Telepsychiatry has been reported to be feasible in the delivery of mental health services across an array of populations. ${ }^{41,42}$ Nevertheless, many barriers have been described including user acceptance and satisfaction, resistance among some providers, concern about interrupting existing referral patterns, technological problems, scheduling delays, as well as potential medico-legal issues. In addition, a recent report from the American Telemedicine Association suggests that payment and coverage for services delivered via telemedicine are one of the biggest challenges for telemedicine adoption. ${ }^{43}$ The report emphasizes that patients and providers may encounter a patchwork of arbitrary insurance requirements and disparate payment streams that do not allow them to fully take advantage of telemedicine. Finally, although rarely described, in one study of patients with psychosis, some actually incorporated videoconferencing into their delusions. $^{40}$

The literature on cost-effectiveness is less conclusive, with one study reporting that telepsychiatry was found to be $10 \%$ less expensive than face-to-face treatment, ${ }^{28}$ while other studies reported that telepsychiatry is more expensive than face-to-face assessment. ${ }^{44}$ The issue of cost-effectiveness remains complex considering the multitude of factors that affect direct and indirect costs. ${ }^{45}$ While telepsychiatry requires additional technology and use of bandwidth, which can be costly, its use also reduces travel costs for patients and their families when psychiatric services are not available locally. Studies take these direct and indirect costs into account to varying degrees, which could perhaps explain the discrepancy in the literature around cost-effectiveness. A recent review that included a summary of 21 studies of telepsychiatry cost effectiveness also noted that services with high volumes of service are more likely to demonstrate cost savings. ${ }^{27}$ 


\section{Telepsychiatry in special populations \\ Child and adolescent}

There is a small and heterogeneous body of research examining telepsychiatry's efficacy in diagnosing and treating young people. In a sample of 23 children, face-to-face and videoconference assessments resulted in comparable diagnoses in children aged $4-16$ years. ${ }^{46}$ Among those aged 14-30 years with early psychosis, telepsychiatry was a reliable medium to administer a battery of neuropsychological and clinical measures. ${ }^{47}$ Other work demonstrated that telepsychiatry can be reliably used to implement CBT for childhood depression and obsessive-compulsive disorder as well as behavioral interventions for tic disorder. ${ }^{48-50}$

A larger body of work has focused on patient, provider, and caregiver satisfaction with telepsychiatry. Most caregivers and patients are satisfied with diagnostic assessments and treatment via telepsychiatry. ${ }^{50-53}$ A number of children and adolescents preferred telepsychiatry assessment over face to face assessments. ${ }^{46-48,51,54}$ Adolescents in rural communities preferred to see practitioners from outside their home communities, and clinicians felt children with autism spectrum disorders, social anxiety, or histories of trauma had more comfort with videoconference assessments. ${ }^{54}$ Some clinicians expressed a preference for face-to-face assessments while others felt they could capably manage difficult situations using videoconferencing. ${ }^{46,51}$

Telepsychiatry can increase access to child and adolescent psychiatry in rural settings and among hard-to-reach populations..$^{49,52,56,57}$ A program evaluation of a school-based telepsychiatry initiative demonstrated that school-based provision of telemental health services can help decrease isolation of school-based clinicians and promote mental health access for at-risk youth in urban settings. ${ }^{58}$ Parents found that being able to access services in their home community decreased stress and led to less missed work. ${ }^{47,50}$ This was hypothesized to contribute to stronger family units and greater connection of children and families to local communities. ${ }^{52}$ Telepsychiatry was also found to strengthen service provision locally, not only through increased access, but also through the increased skill and confidence that mental health professionals developed through connection with remote specialists. ${ }^{52,58}$

Initial literature on telepsychiatry services for young people focused on technical challenges, ${ }^{57}$ but recently the focus is more often on health systems concerns. An effective child telepsychiatry service has been described as one where effort was made to build in-person connections between rural and specialist professionals, where there was strong centralized administrative support, adequate local resources to implement recommendations, and where both service providers in target communities and telepsychiatrists felt supported. ${ }^{52,59,60}$ Providing consultations without attention to capacity building runs the risk of poor uptake by communities who do not see benefits of the service, decreased utilization by mental health agencies, and burnout among local providers and telepsychiatrists. ${ }^{56,59,60}$ The latter point is relevant to the successful development of services for all populations.

\section{Older adults}

The use of telepsychiatry has also been studied in a number of different geriatric settings including nursing homes, hospitals, and community services. There has been considerable interest in the feasibility of utilizing videoconferencing with older adults, some of whom may be suffering from cognitive impairment or hearing/visual difficulties. A recent paper by Ramos-Ríos et al provided a comprehensive review of telepsychogeriatrics based on a review of 45 relevant papers. ${ }^{61}$ Nine studies from the US and Asia provided insights into the process of consultation to nursing homes. These studies suggested a high level of satisfaction by users and staff and some reports of improved outcomes. One study suggested that the service resulted in reduced transfers to general hospitals, ${ }^{62} \mathrm{a}$ critically important metric. Another study noted significant cost and time savings. ${ }^{63}$ Ten papers focused on the reliability of diagnostic assessments via videoconference compared to face-to-face. The papers indicated good interrater reliability for the diagnosis of dementia and for the utilization of a variety of assessment tools including the Brief Psychiatric Rating Scale, the Hamilton Depression Rating Scale, the Geriatric Depression Scale, the MMSE, the Blessed Dementia Scale, and the Short Portable Mental Status Questionnaire. Another group of papers that focused solely on cognitive assessments did find some differences. For example, in two studies of the MMSE, scores were somewhat higher for in-person assessments, although in one the correlation was high $(r=0.95)$. In another study, differences were small except for the scores of the Clock Drawing test. It should be noted that in some studies, patients reported a preference for in-person assessment, but in general videoconference was seen as an acceptable alternative. A recent paper by Conn et al reported on the program evaluation of a ten-year-old service, linking a geriatric teaching hospital and a rural community outreach service about 2,000 km away. ${ }^{64}$ Feedback from evaluations by clients and staff, a survey of referring physicians, and a series of focus groups yielded high levels of satisfaction 
and also provided insights into the necessary ingredients to develop and sustain such a program.

\section{Military populations, international settings, and cultural considerations}

Telepsychiatry's promise is its potential to improve access to mental health services for hard-to-serve populations. In some immigrant and refugee communities, patients can have difficulty accessing culturally sensitive mental health care in their native language. One application of telepsychiatry has been to connect physicians and patients who speak the same language and who may be of a similar cultural background. ${ }^{65-68}$ Patients report preferring to receive health care from a provider who speaks the same language rather than through interpretation, citing confidentiality concerns and concerns about the accuracy of translations. ${ }^{65,67}$ In addition, telepsychiatry allows patients to receive care in a primary care setting, which may increase help-seeking. ${ }^{66}$

Military personnel describe preferring to access mental health services from military-affiliated professionals as they feel a shared understanding is important. ${ }^{69}$ Telepsychiatry has been used in this population to improve access to mental health support for personnel living some distance from military bases and to support mental health professionals at bases that are over-burdened. ${ }^{69,70}$

There is a large body of work examining the use of telepsychiatry in forensic settings. Telepsychiatry has also been used to increase mental health services to inmates in the correctional system and has been shown to be frequently used, cost-effective, and satisfactory to patients and physicians in this setting, though some youth expressed concern about confidentiality. ${ }^{56,71,72}$ In addition, a recent review summarized how in Australia, Canada, the United Kingdom, and the United States, telepsychiatry has been used for assessments of fitness to stand trial, or adjudicative competence. ${ }^{73}$ This review highlighted how telepsychiatry has been particularly used in Australia for the purposes of identifying potentially mentally ill offenders who might benefit from court diversion or pretrial psychiatric assessment. ${ }^{73}$

To date, there has been limited application of telepsychiatry to provide cross-border mental health care and minimal research in low and middle income countries. ${ }^{74}$ Synchronous telepsychiatry requires specific technology which may limit its application where power sources are unreliable or where land-based telephone and Internet services are lacking. ${ }^{75}$ Although telepsychiatry was found to be an acceptable method of receiving health care by patients from various cultural backgrounds, such application presents specific challenges. ${ }^{66,68,76}$ For example, eye contact and body language have varying cross-cultural meaning, and so the camera angle and zoom may need to be considered. ${ }^{76}$ Members providing telepsychiatry to cultural communities that they do not belong to should approach such encounters with "humility" and be open to understanding and accepting cultural differences. ${ }^{77}$ In addition, occasional in-person visits may be necessary to demonstrate commitment to the project and to the community. ${ }^{77}$

\section{Emerging approaches and technologies}

Asynchronous telepsychiatry was first reported by Yellowlees et al in 2010. ${ }^{10}$ The feasibility study included sixty patients with non-emergency problems. Video recordings lasting 20-30 minutes were uploaded along with other patient data to a web-based record. Two psychiatrists provided consultations to primary care physicians based on a review of the recordings. The most common diagnoses were mood disorders, anxiety disorders, and substance-use disorders. The psychiatrists recommended short-term medication changes in $95 \%$ of the patients as well as recommendations for possible future changes. A cost analysis comparing synchronous telepsychiatry, asynchronous telepsychiatry, and in-person psychiatric consultations in a primary care setting found that asynchronous telepsychiatry became the most cost-effective of the three models when more than 249 consultations were provided. ${ }^{78}$ A recent review of health information technologies such as smartphones, apps or desktop software, and the Internet emphasized the promise of utilizing these technologies to increase reach, especially in rural and low-income regions. ${ }^{79}$ However, the authors also highlight the limited evidence in support of these approaches to date and the need for more research in the field. Some recent studies are promising such as a project comparing the use of Internet-based CBT adapted for mobile phone administration with a guided self-help treatment based on interpersonal psychotherapy for social anxiety disorder. ${ }^{80}$ In this study, CBT performed significantly better than interpersonal psychotherapy. Other studies include the use of a mobile phone short message service to reduce alcohol consumption among alcohol-dependent patients $;{ }^{81}$ the use of smartphone data as objective measures of bipolar disorder symptoms; ${ }^{82}$ and the use of text messaging to track symptoms of PTSD ${ }^{83}$ and to support smoking cessation. ${ }^{84}$ Finally, an Australian randomized controlled trial demonstrated the effectiveness of a mobile phone and web-based program on symptom and functional outcomes 
for people with mild-to-moderate depression, anxiety, and stress. $^{85}$

\section{Future directions}

The continuing disparities in the availability of mental health services around the globe and within all nations provide the impetus for further expansion and development of telepsychiatry services. As demonstrated in this paper, there is now a substantial body of evidence to support the feasibility and effectiveness of telepsychiatry. Although some barriers remain, the almost ubiquitous availability of cheap videoconferencing will provide additional fuel to the growth of the field. Ensuring secure connections with protection of privacy will become even more important with further expansion. The field is also witnessing a greater focus on ongoing treatment and psychotherapy in addition to assessment and consultation. The adoption of more convenient and efficient approaches such as utilizing personal computers and tablets, and asynchronous store-and-forward models are also likely to grow as described above. The successful use of videophones has been described for intensive case management of psychiatric outpatients in their homes. ${ }^{86}$ Education of future health care providers regarding how to optimally deliver these services will also become increasingly important. ${ }^{87}$ The broader field of E-mental health including the provision of information and education via the Internet, the seamless sharing of electronic records, and the use of Email in clinical practice are all contributing to a rapidly changing clinical arena. There is also recent evidence that telepsychiatry pilot programs are beginning in developing countries such as South Africa ${ }^{75}$ and India, ${ }^{88}$ and in the Middle East. ${ }^{89}$ Hopefully, health care funders will invest the required funds to support the growth of this exciting field across the globe, driven by the need to reduce fragmentation of health care systems, improve timely access to care, and meet rising consumer expectations.

\section{Disclosure}

The authors report no conflicts of interest in this work.

\section{References}

1. Wooton R, Yellowlees P, McLaren P, editors. Telepsychiatry and E-mental Health. London: Royal Society of Medicine Press; 2003.

2. Evidence Based Practice for Telemental Health [webpage on the Internet]. Washington (DC): American Telemedicine Association; 2009. Available from: http://www.americantelemed.org/resources/ telemedicine-practice-guidelines/telemedicine-practice-guidelines/evidence-based-practice-for-telemental-health\#.VOVgqrDF9rg. Accessed February 18, 2015.

3. Wittson CL, Affleck DC, Johnson V. Two-way television in group therapy. Ment Hosp. 1961;12:22-23.
4. Dwyer TF. Telepsychiatry: psychiatric consultation by interactive television. Am J Psychiatry. 1973;130(8):865-869.

5. World Health Organization. Telemedicine: Opportunities and developments in member states. Report on the second global survey on eHealth. Geneva: WHO Press; 2010.

6. Telemedicine Frequently Asked Questions (FAQs) [webpage on the Internet]. Washington (DC): American Telemedicine Association. Available from: http://www.americantelemed.org/about-telemedicine/ faqs\#.VMeuM9LF94V. Accessed January 25, 2015.

7. Urness D, Hailey D, Delday L, Callanan T, Orlik H. The status of telepsychiatry services in Canada: a national survey. J Telemed Telecare. 2004;10(3):160-164.

8. Kavanagh S, Hawker F. The fall and rise of the South Australian telepsychiatry network. J Telemed Telecare. 2001;7 Suppl 2:41-43.

9. Ontario Telemedicine Network. Embarking on the Journey for Virtual Care: 2012/13 Annual Report. Ontario Telemedicine Network; 2013. Available from: https://otn.ca/sites/default/files/otn-annual-report2012-13.pdf. Accessed January 25, 2015.

10. Yellowlees PM, Odor A, Parish MB, Iosif AM, Haught K, Hilty D. A feasibility study of the use of asynchronous telepsychiatry for psychiatric consultations. Psychiatr Serv. 2010;61(8):838-840.

11. Singal AG, Higgins PD, Waljee AK. A primer on effectiveness and efficacy trials. Clin Transl Gastroenterol. 2014;5:e45.

12. El-Serag HB, Talwalkar J, Kim WR. Efficacy, effectiveness, and comparative effectiveness in liver disease. Hepatol. 2010;52(2): 403-407.

13. Yellowlees P, Shore J, Roberts L; American Telemedicine Association. Practice guidelines for videoconferencing-based telemental health October 2009. Telemed J E Health. 2010;16(10):1074-1089.

14. Telepsychiatry: Professional Practice Standards and Guides for Telepsychiatry [webpage on the Internet]. Melbourne: The Royal Australian and New Zealand College of Psychiatrists; 2013. Available from: http:// www.ranzcp.org/Files/Resources/RANZCP-Professional-PracticeStandards-and-Guides.aspx. Accessed January 25, 2015.

15. Chipps J, Ramlall S, Mars M. Practice guidelines for videoconferencebased telepsychiatry in South Africa. Afr J Psychiatry (Johannesbg). 2012;15:271-282.

16. CPA Clinical Guidelines and Position Papers: Telepsychiatry [webpage on the Internet]. Ottawa: Canadian Psychiatric Association; 2013. Available from: http://ww1.cpa-apc.org:8080/publications/position_ papers/telepsychiatry.asp. Accessed January 25, 2015.

17. Myers K, Cain S; Work Group on Quality Issues; American Academy of Child and Adolescent Psychiatry Staff. Practice parameter for telepsychiatry with children and adolescents. J Am Acad Child Adolesc Psychiatry. 2008;47:1468-1483.

18. European Momentum for Mainstreaming Telemedicine Deployment in Daily Practice. Momentum; 2014. List of critical success factors dated 6th May 2014. Available from: http://telemedicine-momentum. eu/wp-content/uploads/2014/05/Momentum_CSFs_v01_6may2014. pdf. Accessed February 18, 2015.

19. Hsiung RC. Suggested principles of professional ethics for the online provision of mental health services. Stud Health Technol Inform. 2001;84(Pt 2):1296-1300.

20. The Australian Psychological Society Ltd. Guidelines for Providing Psychological Services and Products Using the Internet and Telecommunications Technologies. Melbourne: Australian Psychological Society; 2011. Available from: http://aaswsocialmedia.wikispaces.com/file/view/ EG-Internet.pdf. Accessed January 25, 2015.

21. Kane B, Sands DZ. Guidelines for the clinical use of electronic mail with patients. The AMIA Internet Working Group, Task Force on Guidelines for the Use of Clinic-Patient Electronic Mail. J Am Med Inform Assoc. 1998;5(1):104-111.

22. Shore JH, Brooks E, Savin D, Orton H, Grigsby J, Manson SM. Acceptability of telepsychiatry in American Indians. Telemed $J E$ Health. 2008;14(5):461-466.

23. Hyler SE, Gangure DP, Batchelder ST. Can telepsychiatry replace in-person psychiatric assessments? A review and meta-analysis of comparison studies. CNS Spectr. 2005;10(5):403-413. 
24. Amarendran V, George A, Gersappe V, Krishnaswamy S, Warren C. The reliability of telepsychiatry for a neuropsychiatric assessment. Telemed J E Health. 2011;17:223-225.

25. McEachern W, Kirk A, Morgan DG, Crossley M, Henry C. Reliability of the MMSE administered in-person and by telehealth. Can J Neurol Sci. 2008;35(5):643-646.

26. Turner TH, Horner MD, Vankirk KK, Myrick H, Tuerk PW. A pilot trial of neuropsychological evaluations conducted via telemedicine in the Veterans Health Administration. Telemed J E Health. 2012;18(9): $662-667$.

27. Hilty DM, Ferrer DC, Parish MB, Johnston B, Callahan EJ, Yellowlees PM. The effectiveness of telemental health: a 2013 review. Telemed J E Health. 2013;19:444-454.

28. O’Reilly R, Bishop J, Maddox K, Hutchinson L, Fisman M, Takhar J. Is telepsychiatry equivalent to face-to-face psychiatry? Results from a randomized controlled equivalence trial. Psychiatr Serv. 2007;58(6): 836-843.

29. Ruskin PE, Silver-Aylaian M, Kling MA, et al. Treatment outcomes in depression: comparison of remote treatment through telepsychiatry to in-person treatment. Am J Psychiatry. 2004;161(8):1471-1476.

30. De Las Cuevas C, Arredondo MT, Cabrera MF, Sulzenbacher H, Meise U. Randomized clinical trial of telepsychiatry through videoconference versus face-to-face conventional psychiatric treatment. Telemed J E Health. 2006;12(3):341-350.

31. Dellifraine JL, Dansky KH. Home-based telehealth: a review and meta-analysis. J Telemed Telecare. 2008;14(2):62-66.

32. Hailey D, Roine R, Ohinmaa A. The effectiveness of telemental health applications: a review. Can J Psychiatry. 2008;53(11):769-778.

33. Backhaus A, Agha Z, Maglione ML, et al. Videoconferencing psychotherapy: a systematic review. Psychol Serv. 2012;9(2):111-131.

34. Frueh BC, Monnier J, Yim E, Grubaugh AL, Hamner MB, Knapp RG. A randomized trial of telepsychiatry for post-traumatic stress disorder. J Telemed Telecare. 2007;13(3):142-147.

35. Yellowlees P, Burke MM, Marks SL, Hilty DM, Shore JH. Emergency telepsychiatry. J Telemed Telecare. 2008;14(6):277-281.

36. Sorvaniemi M, Santamäki O. Telepsychiatry in emergency consultations. J Telemed Telecare. 2002;8(3):183-184.

37. Sorvaniemi M, Ojanen E, Santamäki O. Telepsychiatry in emergency consultations: a follow-up study of sixty patients. Telemed J E Health. 2005;11(4):439-441.

38. Shore JH, Hilty DM, Yellowlees P. Emergency management guidelines for telepsychiatry. Gen Hosp Psychiatry. 2007;29(3):199-206.

39. McLaren P, Ball CJ, Summerfield AB, Watson JP, Lipsedge M. An evaluation of the use of interactive television in an acute psychiatric service. J Telemed Telecare. 1995;1:79-85.

40. Grady B, Singleton M. Telepsychiatry "coverage" to a rural inpatient psychiatric unit. Telemed J E Health. 2011;17(8):603-608.

41. Shore JH. Telepsychiatry: videoconferencing in the delivery of psychiatric care. Am J Psychiatry. 2013;170(3):256-262.

42. Yellowlees P, Marks S, Hilty D, Shore JH. Using e-health to enable culturally appropriate mental healthcare in rural areas. Telemed $J E$ Health. 2008;14(5):486-492.

43. Thompson L, Capistrant G. 50 State Telemedicine Gaps Analysis Coverage and Reimbursement. Washington (DC): American Telemedicine Association; 2014. Available from: http://www.americantelemed. org/docs/default-source/policy/50-state-telemedicine-gaps-analysis--coverage-and-reimbursement.pdf?sfvrsn=6. Accessed January 25, 2015.

44. Modai I, Jabarin M, Kurs R, Barak P, Hanan I, Kitain L. Cost effectiveness, safety, and satisfaction with video telepsychiatry versus faceto-face care in ambulatory settings. Telemed J E Health. 2006;12(5): $515-520$.

45. Luxton DD. Considerations for planning and evaluating economic analyses of telemental health. Psychol Serv. 2013;10(3):276-282.

46. Elford R, White H, Bowering R, et al. A randomized, controlled trial of child psychiatric assessments conducted using videoconferencing. J Telemed Telecare. 2000;6(2):73-82.
47. Stain H, Payne K, Thienel R, Michie P, Carr V, Kelly B. The feasibility of videoconferencing for neuropsychological assessments of rural youth experiencing early psychosis. J Telemed Telecare. 2011;17(6): 328-331.

48. Nelson E, Barnard M, Cain S. Treating childhood depression over videoconferencing. Telemed J E Health. 2003;9(1):49-55.

49. Turner C, Heyman I, Futh A, Lovell K. A pilot study of telephone cognitive-behavioural therapy for obsessive-compulsive disorder in young people. Behav Cogn Psychother. 2009;37(4):469-474.

50. Himle MB, Freitag M, Walther M, Franklin SA, Ely L, Woods DW. A randomized pilot trial comparing videoconference versus face-to-face delivery of behavior therapy for childhood tic disorders. Behav Res Ther. 2012;50(9):565-570.

51. Elford DR, White H, St John K, Maddigan B, Ghandi M, Bowering R. A prospective satisfaction study and cost analysis of a pilot child telepsychiatry service in Newfoundland. J Telemed Telecare. 2001;7(2): 73-81.

52. Greenberg N, Boydell KM, Volpe T. Pediatric telepsychiatry in ontario: Caregiver and service provider perspectives. J Behav Heal Serv Res. 2006;33(1):105-111.

53. Myers KM, Valentine JM, Melzer SM. Child and adolescent telepsychiatry: utilization and satisfaction. Telemed $J$ E Health. 2008;14(2):131-137.

54. Pakyurek M, Yellowlees P, Hilty D. The child and adolescent telepsychiatry consultation: can it be a more effective clinical process for certain patients than conventional practice? Telemed J E Health. 2010;16(3): 289-292.

55. Ermer DJ. Experience with a rural telepsychiatry clinic for children and adolescents. Psychiatr Serv. 1999;50(2):260-261.

56. Myers K, Valentine J, Morganthaler R, Melzer S. Telepsychiatry with incarcerated youth. J Adolesc Health. 2006;38(6):643-648.

57. Pesämaa L, Ebeling H, Kuusimäki ML, Winblad I, Isohanni M, Moilanen I. Videoconferencing in child and adolescent telepsychiatry: a systematic review of the literature. J Telemed Telecare. 2004;10(4): 187-192.

58. Grady BJ, Lever N, Cunningham D, Stephan S. Telepsychiatry and school mental health. Child Adolesc Psychiatr Clin NAm. 2011;20(1): 81-94.

59. Wood J, Stathis S, Smith A, Krause J. E-CYMHS: an expansion of a child and youth telepsychiatry model in Queensland. Australas Psychiatry. 2012;20(4):333-337.

60. Myers KM, Vander Stoep A, McCarty CA, et al. Child and adolescent telepsychiatry: variations in utilization, referral patterns, and practice trends. J Telemed Telecare. 2010;16(3):128-133.

61. Ramos-Ríos R, Mateos R, Lojo D, Conn DK, Patterson T. Telepsychogeriatrics: a new horizon in the care of mental health problems in the elderly. Int Psychogeriatr. 2012;24:1708-1724.

62. Lyketsos CG, Roques C, Hovanec L, Jones BN 3rd. Telemedicine use and the reduction of psychiatric admissions from a long-term care facility. J Geriatr Psychiatry Neurol. 2001;14(2):76-79.

63. Rabinowitz T, Murphy KM, Amour JL, Ricci MA, Caputo MP, Newhouse PA. Benefits of a telepsychiatry consultation service for rural nursing home residents. Telemed $J E$ Health. 2010;16(1):34-40.

64. Conn DK, Madan R, Lam J, Patterson T, Skirten S. Program evaluation of a telepsychiatry service for older adults connecting a university-affiliated geriatric center to a rural psychogeriatric outreach service in Northwest Ontario, Canada. Int Psychogeriatr. 2013;25:1795-1800.

65. Mucic D. Transcultural telepsychiatry and its impact on patient satisfaction. J Telemed Telecare. 2010;16(5):237-242.

66. Chong J, Moreno F. Feasibility and acceptability of clinic-based telepsychiatry for low-income Hispanic primary care patients. Telemed $J$ E Health. 2012;18(4):297-304.

67. Ye J, Shim R, Lukaszewski T, Yun K, Kim SH, Ruth G. Telepsychiatry services for Korean immigrants. Telemed J E Health. 2012;18(10): 797-802. 
68. Yeung A, Johnson DP, Trinh NH, Weng WC, Kvedar J, Fava M. Feasibility and effectiveness of telepsychiatry services for chinese immigrants in a nursing home. Telemed J E Health. 2009; 15(4):336-341.

69. Grady BJ, Melcer T. A retrospective evaluation of TeleMental Healthcare services for remote military populations. Telemed $J$ E Health. 2005;11(5):551-558.

70. Detweiler MB, Arif S, Candelario J, et al. A telepsychiatry transition clinic: the first 12 months experience. J Telemed Telecare. 2011;17(6): 293-297.

71. Nelson EL, Zaylor C, Cook D. A comparison of psychiatrist evaluation and patient symptom report in a jail telepsychiatry clinic. Telemed $J E$ Health. 2004;10 Supp1 2:S54-S59.

72. Brodey BB, Claypoole KH, Motto J, Arias RG, Goss R. Satisfaction of forensic psychiatric patients with remote telepsychiatric evaluation. Psychiatr Serv. 2000;51(10):1305-1307.

73. Mars M, Ramlall S, Kaliski S. Forensic telepsychiatry: a possible solution for South Africa? Afr J Psychiatry (Johannesbg). 2012;15: 244-247.

74. Jefee Bahloul H, Mani N. International telepsychiatry: a review of what has been published. J Telemed Telecare. 2013;19(5):293-294.

75. Mars M. Telepsychiatry in Africa - a way forward? Afr J Psychiatry (Johannesbg). 2012;15(4):215, 217.

76. Shore JH, Savin DM, Novins D, Manson SM. Cultural aspects of telepsychiatry. J Telemed Telecare. 2006;12(3):116-121.

77. Volpe T, Boydell KM, Pignatiello A. Mental health services for Nunavut children and youth: evaluating a telepsychiatry pilot project. Rural Remote Health. 2014;14(2):2673.

78. Butler TN, Yellowlees P. Cost analysis of store-and-forward telepsychiatry as a consultation model for primary care. Telemed J E Health. 2012;18(1):74-77.

79. Clarke G, Yarborough BJ. Evaluating the promise of health IT to enhance/expand the reach of mental health services. Gen Hosp Psychiatry. 2013;35(4):339-344.
80. Dagöö J, Asplund RP, Bsenko HA, et al. Cognitive behavior therapy versus interpersonal psychotherapy for social anxiety disorder delivered via smartphone and computer: a randomized controlled trial. J Anxiety Disord. 2014;28(4):410-417.

81. Lucht MJ, Hoffman L, Haug S, et al. A surveillance tool using mobile phone short message service to reduce alcohol consumption among alcohol-dependent patients. Alcohol Clin Exp Res. 2014;38(6) 1728-1736.

82. Faurholt-Jepsen M, Frost M, Vinberg M, Christensen EM, Bardram JE, Kessing LV. Smartphone data as objective measures of bipolar disorder symptoms. Psychiatry Res. 2014;217:124-127.

83. Price M, Ruggiero KJ, Ferguson PL, et al. A feasibility pilot study on the use of text messages to track PTSD symptoms after a traumatic injury. Gen Hosp Psychiatry. 2014;36(3):249-254.

84. Kong G, Ells DM, Camenga DR, Krishnan-Sarin S. Text messagingbased smoking cessation intervention: a narrative review. Addict Behav. 2014;39(5):907-917.

85. Proudfoot J, Clarke J, Birch MR, et al. Impact of a mobile phone and web program on symptom and functional outcomes for people with mild-to-moderate depression, anxiety and stress: a randomized controlled trial. BMC Psychiatry. 2013;13:312.

86. Nieves JE, Godleski LS, Stack KM, Zinanni T. Videophones for intensive case management of psychiatric outpatients. J Telemed Telecare. 2009; 15:51-54.

87. Sunderji N, Crawford A, Jovanovic M. Telepsychiatry in graduate medical education: a narrative review. Acad Psychiatry. 2015;39(1): 55-62.

88. Malhotra S, Chakrabarti S, Shah R. Telepsychiatry: Promise, potential, and challenges. Indian J Psychiatry. 2013;55:3-11.

89. Jefee-Bahloul H. Telemental health in the middle East: overcoming the barriers. Front Public Health. 2014;2:86.
Smart Homecare Technology and TeleHealth

\section{Publish your work in this journal}

Smart Homecare Technology and TeleHealth is an international, peer-reviewed, open access online journal publishing original research, reviews, editorials and commentaries on the application of technology to support people and patients at home and in assisted living centers to optimize healthcare and management resources. Specific topics in the journal include: Development and application of

\section{Dovepress}

devices within the home and embedded in appliances; Healthcare provider communication and education tools; and drug ordering and adherence. The manuscript management system is completely online and includes a very quick and fair peer-review system, which is all easy to use. Visit http://www.dovepress.com/ testimonials.php to read real quotes from published authors. 